\title{
A Pilot Survey on Hygienic-Sanitary Characteristics of Ready-To-Eat Sauces and Pesto
}

\author{
Giuseppina Caggiano ${ }^{1, *} \mathbb{D}$, Giusy Diella ${ }^{1}$, Paolo Trerotoli ${ }^{1}\left[\right.$, Marco Lopuzzo ${ }^{1}$, \\ Francesco Triggiano ${ }^{1}$, Massimo Ricci ${ }^{2}$, Vincenzo Marcotrigiano ${ }^{3}$, Maria Teresa Montagna ${ }^{1, *}$ (i) \\ and Osvalda De Giglio ${ }^{1}$ (I)
}

1 Department of Biomedical Science and Human Oncology Hygiene Section-University of Bari Aldo Moro, Medical School, Piazza G. Cesare 11, 70124 Bari, Italy; giusy.diella@uniba.it (G.D.); paolo.trerotoli@uniba.it (P.T.); marcolopuzzo@gmail.com (M.L.); francesco.triggiano@uniba.it (F.T.); osvalda.degiglio@uniba.it (O.D.G.)

2 ARPA Puglia, Regional Agency of the Environmental Prevention and Protection, Department of Brindisi Operative Unit of Food and Drink, via Galanti, 16, 72100 Brindisi, Italy; m.ricci@arpa.puglia.it

3 Department of Prevention, Food Hygiene and Nutrition Service, Local Health Unit BT, Barletta-Andria-Trani, 76125 Trani, Italy; vincenzo.marcotrigiano@aslbat.it

* Correspondence: giuseppina.caggiano@uniba.it (G.C.); mariateresa.montagna@uniba.it (M.T.M.); Tel.: +39-080-5478-475 (G.C.); +39-080-5478-475 (M.T.M.)

Received: 9 June 2020; Accepted: 9 July 2020; Published: 12 July 2020

\begin{abstract}
In recent years, the chaotic habits of modern life have favored the consumption of quickly prepared meals, using ready-to-eat (RTE) foods and condiments. The aim of this study was to establish the microbiological safety of RTE sauces and pesto from markets analyzed at different stages of shelf life. In the bacterial investigation, all samples were shown to be acceptable, although differences were observed concerning shelf life times. On the other hand, the fungal investigation showed frequent positive results, with concentrations higher than threshold values. Detected microbial diffusion was the lowest when products were far from the expiry date and had just been opened, while high microbial proliferation was observed when analyzing the same package after $48 \mathrm{~h}$, higher than for a product close to the end of its shelf life. This study highlights the discreet microbiological quality of processed and RTE foods, underlining the importance of hygienic-sanitary surveillance of these foods to their shelf life. Consequently, it is necessary to: (1) implement a food control plan for all food categories to carry out risk analysis associated with their consumption; and (2) better adapt the regulations relating to microbiological analysis, and understand the biological significance of each microbial parameter throughout the shelf life of foods.
\end{abstract}

Keywords: ready-to-eat food; sauces and pesto; foodborne diseases; public health; microbiological analysis; fungi

\section{Introduction}

Foodborne diseases (FBDs) are a crucial and growing public health problem worldwide [1], causing significant economic losses and medical costs. Also known as food poisoning, these diseases encompass a wide spectrum of illnesses caused by the ingestion of contaminated foods. The contamination can be caused by different germs (bacteria, viruses and parasites) or chemical agents, and can be linked to environmental contamination, including pollution of water, soil and air. To date, researchers have identified more than 250 FBDs. The Center for Disease Control and Prevention (CDC) estimates that 48 million people get sick from FBDs every year, while 128,000 are hospitalized and 3000 die [2]. According to the latest published data reported by European Union 
(EU) Member States, in 2018, 5146 foodborne outbreaks affected 48,365 people. Salmonellosis was the second-most commonly reported gastrointestinal infection in humans in the EU $(91,857$ cases reported) after campylobacteriosis (246,571 cases); Slovakia, Spain and Poland accounted for $67 \%$ of the 1581 salmonellosis cases, mainly linked to egg consumption [3].

Although the food of animal origin is the main source of documented FBD outbreaks, the number of human cases associated with food of non-animal origin appears to be increasing $[4,5]$.

In recent years, the chaotic habits of modern life have favored the consumption of quickly prepared meals, using ready-to-eat (RTE) foods and condiments, that are capable of satisfying any gastronomic needs. The consumption of mixed salads with vegetables and different ingredients has also increased [6].

As is the case with other RTE foods, salads-often intended as whole meals-are readily available in the refrigerated sections of supermarkets, packaged in plastic bowls [4]. Although current food technologies, innovative packaging systems and the extension of product shelf life contribute to guaranteeing the healthfulness of products intended for increasingly attentive and demanding consumers, it is still difficult to achieve absolute microbiological safety in the food sector. Consequently, the hygienic-sanitary surveillance of RTE foods, especially those with multiple ingredients, is undoubtedly useful for the prevention of infections.

European Commission Regulation No. 852/2004 on the hygiene of foodstuffs provides a risk-based approach to controlling food hygiene $[7,8]$. The regulation requires food business operators to implement a food safety management system, based on hazard analysis and critical control point (HACCP) principles, to maintain good hygienic conditions in the premises and ensure that food staff are trained in good hygiene practices [8]. Concerning microbiological aspects, perishable and RTE food matrices are considered worthy of attention, given their intrinsic conditions favoring microbial proliferation compared to the nutrient capacity of the substrate.

The responsible microorganisms more often found in RTE foods with vegetables are viruses (norovirus and hepatitis A), parasites (Cryptosporidium spp., Giardia spp. and Toxoplasma gondii) and bacteria (Salmonella spp., enterotoxigenic Escherichia coli (ETEC), Campylobacter spp., pathogenic Yersinia enterocolitica and Listeria monocytogenes) $[5,9]$.

There are reports in the literature on FBD outbreaks resulting from the consumption of pesto-a condiment made with basil, oil and sometimes garlic, typical of Liguria (North Italy) — such as an ETEC outbreak in Denmark [10] and outbreaks of cyclosporiasis [11]. The research, and therefore understanding regarding the underlying causes of these outbreaks is still poor, and represents a barrier to effectively addressing this issue. Furthermore, the use of rapid and accurate detection of foodborne pathogens is an international priority to control and prevent foodborne epidemics in humans, and to reduce mortality rates drastically [12].

To date, there are no Italian regulations regarding the microbiological contamination of RTE foods. The aim of this pilot study was to investigate the microbiological safety of RTE sauces and pesto collected from markets and analyzed at different stages of shelf life, evaluating various microbial parameters that are relevant to consumer health.

\section{Materials and Methods}

\subsection{Study Design}

Forty-five samples (14 cheese sauce, 13 basil pesto, 13 pore mushroom sauce and five walnut sauce) were randomly collected from numerous retail stores located in southern Italy. These markets were registered in accordance with EC Reg. 852/2004 [7], and selected their suppliers in order to guarantee safe foodstuffs to consumers. Taking into account the steps of the whole food chain, producers and retailers, each for their own competence, must comply with the sector hygiene prerequisites, guarantee good hygiene and manufacturing practices (GHP, GMP) and apply the provisions of own-check control plans drawn up according to the principles of the HACCP system. Two packages corresponding to 
each production batch were collected for the same brand, for a total of 90 packs, with weight ranging from 140 to $200 \mathrm{~g}$.

Fresh sauces with a shelf life (the date until which the foodstuff retains its specific properties when properly stored) of three months, to be consumed within four days of opening the package, keeping it at $0-4{ }^{\circ} \mathrm{C}$, as reported on the label of three months, which had not undergone sterilization heat treatment, were also analyzed. Samples were packaged in a protective atmosphere and stored in the dark at low relative humidity and under refrigeration $\left(+4{ }^{\circ} \mathrm{C}\right)$ until before analysis.

Only samples without garlic and chili were collected, in order to avoid its documented potential antibacterial effect influencing the results [13-15].

The analysis was carried out in three stages of each sample's shelf life. The first package was subjected to analysis at the time of opening (T0) and then two days after opening (T1), keeping the sample at $+4{ }^{\circ} \mathrm{C}$. The second package of the same lot (remained sealed) was analyzed two days before the manufacturer's expiry date (T2).

\subsection{Bacteria Investigation}

Sauce samples were examined for mesophilic microorganisms (Enterobacteriaceae, Escherichia coli, Bacillus cereus, positive-coagulase Staphylococcus, Clostridium perfringens, Listeria monocytogenes, Salmonella and Listeria monocytogenes) according to the standardized methods detailed below. The microbiology results were interpreted with the microbiological criteria of some RTE foods found in the literature $[8,16]$. Samples were considered non-compliant if they exceeded the acceptable value.

For the quantitative analysis, $10 \mathrm{~g}$ of each sample was added to $90 \mathrm{~mL}$ of Buffered Peptone Water (Biolife Italiana srl, Milano, Italy), homogenized in a stomacher (Biosigma, Cona, Verona, Italy) for $1 \mathrm{~min}$ and subject to three rounds of 10 -fold serial dilution.

To count mesophilic microorganisms, $1 \mathrm{~mL}$ of each dilution was inoculated by the inclusion technique on Plate Count Agar (PCA; Microbiol S.n.c., Cagliari, Italy) and incubated at $30{ }^{\circ} \mathrm{C}$ for $72 \mathrm{~h}$ [17]. Samples with microbial counts of $\leq 10^{6}$ colony forming units/gram (cfu/g) were considered satisfactory, while samples with counts between $10^{6}$ and $<10^{7} \mathrm{cfu} / \mathrm{g}$ were considered acceptable $[8,16]$.

The enumeration of Enterobacteriaceae was performed using the inclusion technique with Violet Red Bile Glucose Agar (VRBG; Microbiol S.n.c., Cagliari, Italy) and incubation at $37^{\circ} \mathrm{C}$ for $24 \mathrm{~h}$ [18]. Typical pink or red-violet colonies with or without halos were inoculated on a nutrient agar (Biolife Italiana srl, Milano, Italy) for $24 \mathrm{~h}$ at $37^{\circ} \mathrm{C}$, and underwent a confirmatory biochemical test with an API (Analytical Profile Index) of 20E (Biomèrieux, Marcy l'Etoile, France) [18]. Enterobacteriaceae counts of $<10^{3} \mathrm{cfu} / \mathrm{g}$ and between $10^{3}$ and $<10^{4} \mathrm{cfu} / \mathrm{g}$ were considered satisfactory and acceptable, respectively $[8,16]$.

The enumeration of E. coli was performed using the inclusion technique with a Tryptone Bile X-glucose (TBX) agar (Microbiol S.n.c., Cagliari, Italy) and incubation at $44^{\circ} \mathrm{C}$ for $24 \mathrm{~h} \mathrm{[19].} \mathrm{Blue} \mathrm{colonies}$ were identified as E. coli [16]. E. coli counts of $<10^{4} \mathrm{cfu} / \mathrm{g}$ and between $10^{4}$ and $<10^{5} \mathrm{cfu} / \mathrm{g}$ were considered satisfactory and acceptable, respectively $[8,16]$.

For evaluation of Bacillus cereus, samples were inoculated on a Mannitol Egg Yolk Polymyxin (MYP) agar (Liofilchem S.r.l, Roseto degli Abruzzi, Italy) and incubated at $30{ }^{\circ} \mathrm{C}$ for $24-48 \mathrm{~h}$ [20]. Suspected blue colonies were transferred to Columbia Agar (Biomèrieux, Marcy l'Etoile, France) and incubated at $37^{\circ} \mathrm{C}$ for $24 \mathrm{~h}$. B. cereus was identified by the presence of typical haemolysis halos [20]. B. cereus counts of $<10^{2} \mathrm{cfu} / \mathrm{g}$ and between $10^{2}$ and $<10^{3} \mathrm{cfu} / \mathrm{g}$ were considered satisfactory and acceptable, respectively $[8,16]$.

The number of coagulase-positive Staphylococcus (later referred to as Staphylococcus aureus) was evaluated by inoculating the samples on a Baird-Parker agar (Biolife Italiana srl, Milano, Italy) [21]. After $48 \mathrm{~h}$ at $37^{\circ} \mathrm{C}$, typical colonies (black and grey, shiny and convex, surrounded by a zone of clearing in the medium) were transferred in a Brain Heart Infusion Broth (Biolife Italiana srl, Milano, Italy) and incubated at $37^{\circ} \mathrm{C}$ for $24 \mathrm{~h}$ for subsequent coagulase testing with rabbit plasma (Liofilchem S.r.l, Roseto degli Abruzzi, Italy) [21]. Strains were identified at the species level by biochemical tests using 
an API Staph (Biomèrieux, Marcy l'Etoile, France). S. aureus counts of cfu $/ \mathrm{g}<10^{2}$ and between $10^{2}$ and $\leq 10^{3} \mathrm{cfu} / \mathrm{g}$ were considered satisfactory and acceptable, respectively $[8,16]$.

For enumeration of Clostridium perfringens, the samples were inoculated on a Tryptose Sulphite Cycloserine (TSC) agar (Biolife Italiana srl, Milano, Italy) and incubated at $37{ }^{\circ} \mathrm{C}$ for $24 \mathrm{~h}$ under anaerobic conditions [22]. Black colonies were subject to further biochemical testing for identification (acid phosphatase; Biolife Italiana srl, Milano, Italy) [22]. C. perfringens counts of $<10 \mathrm{cfu} / \mathrm{g}$ and between 10 and $\leq 10^{2} \mathrm{cfu} / \mathrm{g}$ were considered satisfactory and acceptable, respectively $[8,16]$.

For evaluation of L. monocytogenes, $25 \mathrm{~g}$ of each sample was inoculated in $225 \mathrm{~mL}$ of pre-enrichment Half-Fraser Broth (Biolife Italiana srl, Milano, Italy). After incubation at $30^{\circ} \mathrm{C}$ for $24 \mathrm{~h}, 100 \mu \mathrm{L}$ was transferred to Fraser Broth (Biolife Italiana srl) and incubated at $37^{\circ} \mathrm{C}$ for $24 \mathrm{~h}$ [23]. Each enrichment medium was plated on an Ottaviani and Agosti listeria agar (ALOA; Microbiol S.n.c., Cagliari, Italy) and Palcam agar (Biolife Italiana srl, Milano, Italy) [23]. After incubation at $37^{\circ} \mathrm{C}$ for $24-48 \mathrm{~h}$, the colonies were inoculated into a Columbia agar before proceeding to the confirmation test [23]. No detection in $25 \mathrm{~g}$ was considered satisfactory. Biochemical tests to identify Listeria species were conducted using API Listeria (Biomèrieux, Marcy l'Etoile, France) $[8,16]$.

For enumeration of L. monocytogenes, samples were inoculated in plates with ALOA and incubated at $37^{\circ} \mathrm{C}$ for $24-48 \mathrm{~h}$. Suspected blue colonies were transferred to a Columbia agar (Biomèrieux, Marcy l'Etoile, France) at $37^{\circ} \mathrm{C}$ for $24 \mathrm{~h}$ to observe the presence of haemolysis, and at the same time, xylose and rhamnose tests (Liofilchem S.r.l, Roseto degli Abruzzi, Italy) were performed [24].

For the investigation of possible Salmonella, $25 \mathrm{~g}$ of each sample was added to $225 \mathrm{~mL}$ of Buffered Peptone Water pre-enrichment medium (Biolife Italiana srl, Milano, Italy) [25]. After incubation at $37^{\circ} \mathrm{C}$ for $24 \mathrm{~h}, 100 \mu \mathrm{L}$ of the sample was transferred to a Modified Semisolid Rappaport Vassiliadis (MSRV) agar selective enrichment medium (Microbiol S.n.c., Cagliari, Italy) and incubated at $41.5^{\circ} \mathrm{C}$ for $24 \mathrm{~h}$, and $1 \mathrm{~mL}$ was transferred to the Muller-Kauffmann Tetrathionate-Novobiocin Broth (MKTTn, Biolife Italiana srl, Milano, Italy) at $37^{\circ} \mathrm{C}$ for $24 \mathrm{~h}$ [25]. Then, the enrichment was inoculated into a Xylose Lysine Desoxycholate (XLD) agar specific selective culture medium (Biolife Italiana srl, Milano, Italy) and Salmonella-Shigella (SS) agar (Biomèrieux, Marcy l'Etoile, France) and incubated at $37^{\circ} \mathrm{C}$ for $24 \mathrm{~h}$ and $24-48 \mathrm{~h}$, respectively. Typical black-centered colonies underwent further biochemical testing for identification (API 20E, Biomèrieux, Marcy l'Etoile, France) [25]. No detection in $25 \mathrm{~g}$ was considered satisfactory $[8,16]$.

\subsection{Fungi Investigation}

An aliquot of $10 \mathrm{~g}$ of sample was inoculated in $90 \mathrm{~mL}$ of Buffered Peptone Water (Biolife Italiana srl, Milano, Italy) and homogenized in a stomacher (Biosigma, Cona, Verona, Italy) for $1 \mathrm{~min}$. Three serial decimal dilutions were equipped, and $100 \mathrm{mcl}$ was inoculated on a Dichloran Rose Bengal Chloramphenicol (DRBC) agar (Liofilchem S.r.l, Roseto degli Abruzzi, Italy) and incubated at $25^{\circ} \mathrm{C}$ for five days. Yeast colonies were identified using a semi-automated sugar assimilation system (API ID 32C, Biomèrieux, Marcy l'Etoile, France), and filamentous fungi were identified, evaluating their standard macroscopic and microscopic characteristics [26]. As a reference value for fungi, a concentration of $10^{3} \mathrm{cfu} / \mathrm{g}$ was defined as the threshold value [27]. Samples exceeding the acceptability value were considered non-compliant.

\subsection{Statistical Analysis}

Bacteria, molds and yeasts were counted, and the mean values were used to evaluate differences according to substrata, applying a general mixed model in which data were assumed to have a Poisson distribution. Results are presented as means and 95\% confidence intervals as estimated by the model, after back transformation from the link function (the natural logarithm of the counts). The model had time and package as fixed effects, and the type of sauce was a random effect. The post hoc comparison was adjusted according to Tukey, and the differences in results are shown as an estimated difference on a log scale and a $95 \%$ confidence interval (CI). To evaluate the type of sauce, results are shown 
as estimated covariance parameters of random effects, standard error (SE) and estimated intercepts with SE.

A value of $p<0.05$ was considered to indicate statistical significance. The analysis was conducted using SAS 9.4 (Analytics Software and Solutions; Cary, NC, USA; version for personal use).

\section{Results}

\subsection{Bacterial Investigation}

The results for all 90 samples indicated they were either satisfactory or acceptable, with differences in the count observed for different shelf life times.

The mean bacterial counts for the first package were $61,609 \mathrm{cfu} / \mathrm{g}(95 \% \mathrm{CI}: 22,418-169,311)$ at T0 and 83,617 cfu/g (95\% CI: 30,426-229,793) at T1 (Table 1), corresponding to a difference of -0.305 ( $95 \%$ CI: -0.31 to $-0.30, p<0.0001$ ) that was statistically significantly different. The bacterial count of the second package at T2 was 83,617 cfu/g (95\% CI: 30,426-229,793). All differences with respect to the first package were statistically significant: for T2 vs. T0 the difference was -0.67 (95\% CI: -0.68 to $-0.68, p<0.0001$ ); and for T2 vs. T1 the difference was 0.367 (95\% CI: $0.362-0.372, p<0.0001$ ). The covariance parameter for the bacterial count was 0.68 (SE $=0.48$ ), so the variance among sauces was low, but estimates revealed higher counts for packages of mushroom sauce (intercept 1.2, $\mathrm{SE}=0.41$, $p=0.0269$ ) and lower counts for walnut sauce (intercept $-1.02, \mathrm{SE}=0.41, p=0.048$ ).

The S. aureus count was $132 \mathrm{cfu} / \mathrm{g}$ (95\% CI: 40.72-433.35) for the first package at T0 and $25.3 \mathrm{cfu} / \mathrm{g}$ (95\% CI: 7.75-82.56) at T1; the difference between these two times is 1.6 (95\% CI: 1.6 to 1.7, $p<0.0001$ ). The count for the second package at T2 was $7.5 \mathrm{cfu} / \mathrm{g}$ (95\% CI: 2.3-24.6). This is significantly different from the first package: for T0 vs. T2 it was 2.87 (95\% CI: 2.78-2.96, $p<0.0001)$ with a difference of -1.21 (95\% CI: -1.31 to $-1.12, p<0.0001)$ comparing T1 vs. T2. The covariance parameter for the type of sauce (the random effect) was $0.93(\mathrm{SE}=0.66)$. Only the intercept for mushroom was statistically significant (effect 1.6, $\mathrm{SE}=0.48, p=0.141$ ). Biochemical tests confirmed the identity of the isolated strains as $S$. aureus.

Regarding B. cereus, the counts showed no differences between packages or according to time: the first package at T0 had a count of $3.76 \mathrm{cfu} / \mathrm{g}$ (95\% CI: $2.1-6.8)$, and at T1 it was $4.32 \mathrm{cfu} / \mathrm{g}$ (95\% CI: $2.39-7.82)$. The difference was not statistically significant $(p=0.1815)$. The count for the second package at T2 was $4.32 \mathrm{cfu} / \mathrm{g}$ ( $95 \%$ CI: $2.38-7.81$ ), and did not significantly differ from the first package at T0 $(p=0.7711)$ or at T1 $(p=0.4224)$. The covariance parameter was $0.22 \mathrm{cfu} / \mathrm{g}(\mathrm{SE}=0.16)$, and the intercept for pesto sauce was statistically significant (intercept $=0.61, \mathrm{SE}=0.24, p=0.44$ ).

No Enterobacteriaceae, E. coli, C. perfringens or Salmonella spp. were found in any of the tested samples.

L. monocytogenes was also not isolated, but two pesto samples and one cheese sauce were contaminated with other Listeria species, such L. welshimeri in one sample of pesto, L. innocua in one mushroom sauce sample and L. seeligeri in one sample of cheese sauce, as found in all phases of analysis. 
Table 1. Microorganism counts in analyzed samples, reported as mean and 95\% confidence interval and relative differences.

\begin{tabular}{cccc}
\hline & \multicolumn{3}{c}{ Microorganism Count (cfu/g (95\% CI)) } \\
\hline Microbiologic parameter & T0 & T1 & T2 \\
\hline Mesophilic microorganisms & $61,609(22,418-169,311)^{*}$ & $83,617(30,426-229,793)$ & $83,617(30,426-229,793){ }^{\prime}$ \\
\hline B. cereus & $3.76(2.1-6.8)$ & $4.32(2.39-7.82)$ & $4.32(2.38-7.81)$ \\
\hline Positive-coagulase Staphylococcus & $132(40.72-433.35)^{*}$ & $25.29(7.75-82.56)$ & $7.52(2.3-24.6)^{\prime}$ \\
\hline Molds & $56.61(21.41-165.9)^{*}$ & $183.39(65.89-510.4)$ & $82.63(29.68-229.9)^{\prime}$ \\
\hline Yeasts & $2544.18(1063.3-6087.5)^{*}$ & $8326.45(3479.9-19,923)$ & $3919.9(1638.3-9379.3)^{\prime}$ \\
\hline
\end{tabular}

cfu/g, colony forming units/gram; CI, confidence interval. ${ }^{*} p<0.05 \mathrm{~T} 0$ vs. T1; $p<0.05 \mathrm{~T} 2$ vs. T0 and T2 vs. T1. Enterobacteriaceae, E. coli, C. perfringens, L. monocytogenes and Salmonella are not reported because they were absent in all analyzed samples. 


\subsection{Fungi Investigation}

Regarding yeasts, $22.2 \%$ of samples were non-compliant at $\mathrm{T} 0$ (eight basil pesto, one mushroom sauce and one walnut sauce), $28.9 \%$ at T1 (10 pesto, two mushroom sauce and one walnut sauce) and $35.6 \%$ at T2 (10 pesto, two mushroom sauce, two cheese sauce and two walnut sauce).

The mean for yeasts based on the first package was $2544.18 \mathrm{cfu} / \mathrm{g}$ (95\% CI: 1063.3-6087.5) at T0 and $8326.45 \mathrm{cfu} / \mathrm{g}(95 \% \mathrm{CI} 3479.9-19,923)$ at T1. The difference in the model estimate was -0.438 and was statistically significant (95\% CI: -0.44 to $-0.425, p<0.0001$ ). The estimated count for the second package at T2 was $3919.9 \mathrm{cfu} / \mathrm{g}$ (95\% CI: 1638.3-9379.3), and was significantly different from the first package: for T2 vs. T0 it was -1.186 (95\% CI: -1.192 to $-1.179, p<0.0001)$, while for T2 vs. T1 it was 0.75 (95\% CI: 0.74-0.76, $p<0.0001$ ).

The covariance parameter of the type of sauce for the model applied to yeasts was 0.51 ( $\mathrm{SE}=0.36$ ), so there was not wide variance among types of sauce. The intercept for pesto was $0.92(\mathrm{SE}=0.36$ ), revealing higher counts in pesto, and was the only one that was slightly statistically significant $(p=0.0416)$. Table 2 shows the isolated yeast species.

Regarding molds, $2.2 \%$ of samples were non-compliant at T0 and T1 (one cheese sauce), and $8.9 \%$ at T2 (two mushroom sauce, one cheese sauce and one walnut sauce).

The mean for molds estimated by the model was $56.6 \mathrm{cfu} / \mathrm{g}$ (95\% CI: 21.41-165.9) for the first package at T0 and $183.4 \mathrm{cfu} / \mathrm{g}$ (95\% CI: 65.89-510.4) at T1. The difference of model estimate was -0.33 (95\% CI: -0.37 to $-0.28, p<0.0001)$. For the second package at T2, the mold count was $82.6 \mathrm{cfu} / \mathrm{g}(95 \%$ CI: 29.68-229.9). The difference between T2 and T0 was -1.12 (95\% CI: -1.116 to $-1.08, p<0.0001$ ), while between T2 and T1 it was 0.79 (95\% CI: 0.76-0.3, $p<0.0001$ ).

No large variances were observed among the types of sauce, given the value of the random effect of 0.69 (SE $=0.49$ ), and only the intercept of pesto was statistically significant (estimate effect: -1.36 , $\mathrm{SE}=0.42, p=0.017)$. Aspergillus spp. and Penicillium spp. were the most frequently isolated molds (Table 3). 
Table 2. Yeast species isolated in cheese sauce, basil pesto, mushroom sauce and walnut sauce samples.

\begin{tabular}{ccccc}
\hline & \multicolumn{4}{c}{ Samples (No.) } \\
\cline { 2 - 5 } Isolated Yeasts & Cheese Sauce (14) & Basil Pesto (13) & Mushroom Sauce (13) & Walnut Sauce (5) \\
\cline { 2 - 5 } & & \% Contaminated Samples (No.) & - \\
\hline Saccharomyces cerevisiae & $57.1(8)$ & - & - & - \\
\hline Candida laurentii & $42.8(6)$ & - & - & - \\
\hline Candida lusitaniae & - & $46.1(6)$ & - \\
\hline Candida glabrata & - & $38.4(5)$ & - \\
\hline Candida rugosa & $35.7(5)$ & - & - & - \\
\hline Candida tropicalis & - & $23.1(3)$ & $15(2)$ \\
\hline Candida pelliculosa & - & - & - & $20(1)$ \\
\hline Candida parapsilosis & $14.3(2)$ & - & - & $60(3)$ \\
\hline Candida sake & - & - & - & $20(1)$ \\
\hline Rhodotorula glutinis & $21.4(3)$ & - & - & $40(2)$ \\
\hline Rhodotorula mucilaginosa & - & - & - & - \\
\hline Trichosporon asahii & $21.4(3)$ & - & - & - \\
\hline Cryptococcus laurentii & $14.3(2)$ & - & - & - \\
\hline
\end{tabular}


Table 3. Mold species isolated by cheese sauce, basil pesto, mushroom sauce and walnut sauce samples.

\begin{tabular}{|c|c|c|c|c|}
\hline \multirow{3}{*}{ Isolated Molds } & \multicolumn{4}{|c|}{ Samples (No.) } \\
\hline & Cheese Sauce (14) & Basil Pesto (13) & Mushroom Sauce (13) & Walnut Sauce (5) \\
\hline & \multicolumn{4}{|c|}{ \% Contaminated Samples (No.) } \\
\hline Penicillium spp & $21.4(3)$ & - & - & $80(4)$ \\
\hline Aspergillus spp & $1.2(2)$ & $76.9(10)$ & $61.5(8)$ & $60(3)$ \\
\hline Aspergillus niger & - & $30.7(5)$ & $53.8(7)$ & $20(1)$ \\
\hline Aspergillus flavus & $14.3(2)$ & $38.4(4)$ & $15.4(2)$ & $20(1)$ \\
\hline Aspergillus ochraceus & - & $23.1(3)$ & - & $20(1)$ \\
\hline Cladosporium herbarum & $7.1(1)$ & $61.5(8)$ & - & $60(3)$ \\
\hline Mucorales & $7.1(1)$ & $38.5(5)$ & - & $40(2)$ \\
\hline Alternaria alternata & - & $53.8(7)$ & - & $20(1)$ \\
\hline Fusarium oxysporium & - & $30.77(4)$ & - & $20(1)$ \\
\hline Paecilomyces spp & - & - & - & $20(1)$ \\
\hline Scopulariopsis brevicaulis & - & - & - & $20(1)$ \\
\hline
\end{tabular}




\section{Discussion}

Food safety and consumer protection are a priority for the European Parliament; the publication of the White Paper on Food Safety and the regulations that have evolved over time have allowed the implementation and perfection of a control system, ranging from food production to food contact materials, from obligations regarding traceability to the Rapid Alert System for Food and Feed (RASFF) [7,28-30]. RASFF is the instrument that ensures the rapid transmission of information among the member states, and the recall and withdrawal of foods when food safety risks are detected. Despite advances in legislation, regulations relating to RTE foods are still lacking, especially for those with multiple ingredients. European Community legislation provides for the monitoring of the presence of L. monocytogenes and Salmonella among the food safety criteria for RTE foods [31], leaving out other microbiological parameters.

The study results here highlight a discreet microbiological quality of processed and RTE foods, with an increase of non-compliant products close to the expiry date. This underlines the importance of hygienic-sanitary surveillance of this type of food in relation to its shelf life. In particular, microbial contamination was shown to be low when far from the expiry date and upon opening of the package, while high microbial proliferation was observed when analyzing the same opened package after $48 \mathrm{~h}$. In addition, the product had higher microbial proliferation when at the end of its shelf life, but this was lower than when the product had been opened for $48 \mathrm{~h}$, even if properly stored. Relative to the types of microbial contaminants and the non-compliance of foods, our results show a prevalence of fungi compared to the other investigated microorganisms.

This finding is consistent with the totality of official surveillance data registered at RASFF over the past 10 years [32]. RASFF reported that out of 239 notifications on sauces, the majority (85.7\%) referred to the presence of fragments, additives, chemicals, undeclared ingredients and others. Those relating to microbiological contamination include the presence of bacterial toxins (e.g., botulinum toxin), in which countries reported only 34 notifications. It is very interesting to note that among the notifications for microbiological contamination, $11 / 34$ sauces $(32.34 \%$ ) were contaminated by fungi (yeasts or molds) [32].

In our study, the isolation of Aspergillus flavus is important to underline, as it represents one of the main species responsible for food contamination. It can produce aflatoxin B1 (AFB1) and B2 under favorable conditions (e.g., of temperature and relative humidity) and in improper storage conditions during transport and at stores [33]. Aflatoxins represent one of the main groups of mycotoxins produced in nature. It would be interesting to investigate their presence in these foods to protect the health of consumers from AFB1, a highly dangerous contaminant classified as a human carcinogen (group 1) by the International Agency for Research on Cancer [34].

The detected yeast species were environment-related, and their presence in food is not atypical. Foodborne yeasts, excluding yeasts used as starter cultures, are commonly considered as food spoilage microorganisms [35]. However, some strains, such as C. lusitaniae, C. famata, C. krusei, C. colliculosa, C. parapsilosis and C. tropicalis, which show a relevant similarity to clinical C. albicans, are allocated to a group of potentially risky pathogens [35].

$B$. cereus and $S$. aureus are considered the most common pathogens of FBDs in developed and developing countries. In the period 2009-2015, the United States reported 5760 outbreaks, including 100,939 illnesses, 5699 hospitalizations and 145 deaths [36,37]. B. cereus is ubiquitous in the environment, and can be found in food and food-contact materials [38]. Spores can survive the mild heat treatments given to foods; moreover, B. cereus can develop at $8{ }^{\circ} \mathrm{C}$ and below, posing a danger to human health by the consumption of minimally or inappropriately processed chilled foods [38]. B. cereus toxins also pose a hazard to consumers because they can lead to serious forms of foodborne illnesses [38]. Foods associated with diarrheal food poisoning include soups, sauces and stews, meat products, fish, poultry, milk and dairy products and vegetables [38,39]. In our pilot study, according to the fixed threshold value, we did not detect a high bacterial concentration of $B$. cereus, and therefore the tested foods did not show a considerable risk of exposure to this microorganism. 
S. aureus is a commensal and opportunistic pathogen, and its infection and colonization of livestock and farm workers have been described as possible sources of food contamination [40]. Considering that foodborne S. aureus illness is one of the most frequently reported diseases worldwide, its presence among food workers represents a public health risk, and workers have to put in place proper hygiene and control measures [40].

Considering L. monocytogenes, even if none of our samples were considered non-compliant, different species were isolated. L. innocua was initially considered non-pathogenic (hence its name) [41]. It also was considered non-haemolytic, but recent work has identified a number of haemolytic L. innocua isolates, which suggests that some isolates had presumably been (mis-)classified as L. monocytogenes [41]. Interestingly, some haemolytic L. innocua have been shown to invade (human) Caco-2 cells at the same levels as L. monocytogenes [41,42], while another study characterized the haemolytic L. innocua strain PRL/NW 15B95 as avirulent in a mouse model [41,43]. L. innocua has also been isolated at least once from a fatal human case, further supporting that at least some L. innocua may be able to cause human disease [41,44].

Reports in the literature show that the presence of L. innocua could mask L. monocytogenes and lead to false negative results in research on L. monocytogenes [45]. When L. innocua is present in the test sample, recovery of L. monocytogenes becomes problematic, especially since the two species have similar colony morphologies on isolation media. The use of species differentiating chromogenic media during streak plate isolation can help in the selection, but only if the population differential between L. innocua and L. monocytogenes is relatively small; if the population differential is large, then the resulting isolated colonies will all be the predominant species, which is typically L. innocua $[46,47]$. According to Dailey et al. [47], other non-pathogenic species of Listeria such as L. welshimeri can complicate the recovery of L. monocytogenes, suggesting that competition during selective enrichment is not limited to the presence of just L. innocua.

Although the latest RASFF annual report, published in 2019, documented a foodborne outbreak of Salmonella agona, possibly linked to RTE food in the UK in 2018 [32], from our analysis, Salmonella was not found as a contaminant of sauces and pesto.

Besides Salmonella, neither Enterobacteriaceae, E. coli nor C. perfringens were found, but this must not lead to underestimating the antibacterial power of some ingredients of the pesto and sauces examined. Although a parameter for the selection of the examined foods was the absence of garlic, a food with demonstrated antibacterial activity [12,13], numerous scientific studies also demonstrated the antibacterial power of basil essential oil against these microorganisms $[48,49]$ and of pine nuts [50], which are included in pesto; walnuts [51] and pore mushroom [52] also showed antibacterial properties.

According to the latest Eurobarometer, less than one-third of European citizens rank food poisoning from bacteria among their top five concerns regarding food safety. The number of reported outbreaks suggests that there is an opportunity to raise awareness among consumers, as many foodborne illnesses can be prevented by improving hygiene measures when handling and preparing food [3].

\section{Conclusions}

Our study highlights the discreet microbiological quality of processed and RTE foods. The existence of RASFF notifications for sauces over the years demonstrates that these foods are not free from contamination, and are even sometimes contaminated by potentially lethal organisms such as botulinum toxin.

Considering that molds and yeasts in sauces are the most frequent contaminants, it would be advisable to assess regulations for fungi in this regard. It would be appropriate to place a greater emphasis on trying to better understand the role of fungi in food deterioration and their importance in defining product quality, identifying them at the genus and species level, and setting compliance threshold values for the whole life of commercial products.

It is necessary to implement a national food monitoring control plan for all food categories, and search for more parameters in order to conduct a risk analysis associated with their consumption. 
This would allow for better adaptation to the regulations related to microbiological analysis, and a better understanding of the biological significance of each microorganism throughout the shelf life of food.

Author Contributions: G.C., M.T.M. and O.D.G. conceived the study. M.R., V.M., F.T. and M.L. collected and analyzed the food samples. G.C., M.T.M., O.D.G. and G.D. wrote the manuscript. P.T. statistically analyzed the results. All authors have read and agreed to the final version of the manuscript.

Funding: This research received no external funding.

Conflicts of Interest: The authors declare no conflicts of interest.

\section{References}

1. World Health Organization. Available online: https://www.who.int/topics/foodborne_diseases/en/ (accessed on 11 May 2020).

2. Centers for Disease Control and Prevention. Available online: https://www.cdc.gov/foodborneburden/index. html (accessed on 11 May 2020).

3. European Food Safety Authority. Available online: https://www.efsa.europa.eu/en/news/salmonella-mostcommon-cause-foodborne-outbreaks-european-union (accessed on 11 May 2020).

4. Söderqvist, K. Is your lunch salad safe to eat? Occurrence of bacterial pathogens and potential for pathogen growth in pre-packed ready-to-eat mixed-ingredient salads. Infect. Ecol. Epidemiol. 2017, 7, 1407216. [CrossRef]

5. EFSA Panel on Biological Hazards (BIOHAZ). Scientific Opinion on the risk posed by pathogens in food of non-animal origin. Part 1 (outbreak data analysis and risk ranking of food/pathogen combinations). EFSA J. 2013, 11, 3025. [CrossRef]

6. Little, C.L.; Gillespie, I.A. Prepared salads and public health. J. Appl. Microbiol. 2008, 105, 1729-1743. [CrossRef] [PubMed]

7. Corrigendum to Regulation (EC) No 852/2004 of the European Parliament and of the Council of 29 April 2004 on the hygiene of foodstuffs. OJEU 2004, 139, 1-54.

8. Meldrum, R.J.; Little, C.L.; Sagoo, S.; Mithani, V.; McLauchlin, J.; de Pinna, E. Assessment of the microbiological safety of salad vegetables and sauces from kebab take-away restaurants in the United Kingdom. Food Microbiol. 2009, 26, 573-577. [CrossRef]

9. Gorni, C.; Allemand, D.; Rossi, D.; Mariani, P. Microbiome profiling in fresh-cut products. Trends Food Sci. Technol. 2015, 46, 295-301. [CrossRef]

10. Pakalniskiene, J.; Falkenhorst, G.; Lisby, M.; Madsen, S.B.; Olsen, K.E.; Nielsen, E.M.; Mygh, A.; Boel, J.; Mølbak, K. A foodborne outbreak of enterotoxigenic E. coli and Salmonella Anatum infection after a high-school dinner in Denmark, November 2006. Epidemiol. Infect. 2009, 137, 396-401. [CrossRef]

11. Chalmers, R.M.; Nichols, G.; Rooney, R. Foodborne outbreaks of cyclosporiasis have arisen in North America. Is the United Kingdom at risk? Commun. Dis. Public Health 2000, 3, 50-55.

12. Wu, Q.; Zhang, Y.; Yang, Q.; Yuan, N.; Zhang, W. Review of Electrochemical DNA Biosensors for Detecting Food Borne Pathogens. Sensors 2019, 19, 4916. [CrossRef]

13. Somrani, M.; Inglés, M.-C.; Debbabi, H.; Abidi, F.; Palop, A. Garlic, Onion, and Cinnamon Essential Oil Anti-Biofilms' Effect against Listeria monocytogenes. Foods 2020, 9, 567. [CrossRef]

14. Bhatwalkar, S.B.; Gound, S.S.; Mondal, R.; Srivastava, R.K.; Anupam, R. Anti-biofilm and Antibacterial Activity of Allium sativum Against Drug Resistant Shiga-Toxin Producing Escherichia coli (STEC) Isolates from Patient Samples and Food Sources. Indian J. Microbiol. 2019, 59, 171-179. [CrossRef] [PubMed]

15. Bacon, K.; Boyer, R.; Denbow, C.; O'Keefe, S.; Neilson, A.; Williams, R. Evaluation of different solvents to extract antibacterial compounds from jalapeño peppers. Food Sci. Nutr. 2016, 5, 497-503. [CrossRef]

16. Linee Guida per L'analisi del Rischio nel Campo Della Microbiologia Degli Alimenti, Regione Piemonte 2013. Available online: https://www.ceirsa.org/docum/allegato_punto4.pdf (accessed on 4 May 2020).

17. Microbiologia Della Catena Alimentare-Metodo Orizzontale per la Conta dei Microrganismi-Parte 1: Conta Delle Colonie a $30^{\circ} \mathrm{C}$ con la Tecnica Dell'inseminazione in Profondità. UNI EN ISO 4833-1:2013. 3 October 2013. 
18. Microbiology of the Food Chain-Horizontal Method for the Detection and Enumeration of Enterobacteriaceae-Part 2: Colony-count Technique. ISO 21528-2:2017. June 2017.

19. Microbiologia di Alimenti e Mangimi per Animali-Metodo Orizzontale per la Conta di Escherichia coli beta Glucuronidasi-positiva-Parte 2: Tecnica Della Conta Delle Colonie a $44{ }^{\circ} \mathrm{C}$ che Utilizza 5-bromo-4-cloro-3Indolil beta-D-glucuronide. UNI ISO 16649-2:2010. 28 April 2010.

20. Microbiologia di Alimenti e Mangimi per Animali-Metodo Orizzontale per la Conta di Bacillus Cereus Presunto-Tecnica Della Conta Delle Colonie a $30^{\circ} \mathrm{C}$. UNI EN ISO 7932:2005. 1 April 2005.

21. Microbiologia di Alimenti e Mangimi per Animali-Metodo Orizzontale per la Conta di Stafilococchi Coagulasi-positivi (Staphylococcus Aureus e Altre Specie)—Parte 1: Tecnica che Utilizza il Terreno Agar Baird-Parker. UNI EN ISO 6888-1:2018. 27 September 2018.

22. Microbiologia di Alimenti e Mangimi per Animali-Metodo Orizzontale per la Conta di Clostridium Perfringens-Tecnica Della Conta Delle Colonie. UNI EN ISO 7937:2005. 1 March 2005.

23. Microbiology of the Food Chain-Horizontal Method for the Detection and Enumeration of Listeria Monocytogenes and of Listeria spp. Detection Method. ISO 11290-1:2017. May 2017.

24. Microbiology of the Food Chain-Horizontal Method for the Detection and Enumeration of Listeria Monocytogenes and of Listeria spp. Enumeration Method. ISO 11290-2:2017. May 2017.

25. Microbiology of the Food Chain-Horizontal Method for the Detection, Enumeration and Serotyping of Salmonella Detection of Salmonella spp. ISO 6579-1:2017. February 2017.

26. De Hoog, G.S.; Guarro, J.; Gené, J.; Figueras, M.J.; Vitale, R.G. Atlas of Clinical Fungi: Electronic Version 3.1; Centraalbureau voor Schimmelcultures (CBS): Utrecht, The Netherlands, 2019; Available online: http://www.clinicalfungi.org (accessed on 11 May 2020).

27. Dağ, A. Assessment of microbiological quality of ready-to-eat foods in institutions providing mass feeding. Prog. Nutr. 2020, 22, 68-74.

28. Commission of the European Communities. White Paper on Food Safety; European Community: Brussels, Belgium, 2000; pp. 1-52.

29. Regulation (EC) No 178/2002 of the European Parliament and of the Council of 28 January 2002 laying down the general principles and requirements of food law, establishing the European Food Safety Authority and laying down procedures in matters of food safety. OJEU 2002, 31, 1-24.

30. Marcotrigiano, V.; Lanzilotti, C.; Rondinone, D.; De Giglio, O.; Caggiano, G.; Diella, G.; Orsi, G.B.; Montagna, M.T.; Napoli, C. Food labelling: Regulations and Public Health implications. Ann. Ig. 2018, 30, 220-228. [CrossRef] [PubMed]

31. Commission Regulation (EC) No 2073/2005 of 15 November 2005 on microbiological criteria for foodstuffs. OJEU 2005, 338, 1-26.

32. Rapid Alert System for Food and Feed (RASFF) Portal. Available online: https://webgate.ec.europa.eu/rasffwindow/portal/?event=searchResultList (accessed on 11 May 2020).

33. Diella, G.; Caggiano, G.; Ferrieri, F.; Ventrella, A.; Palma, M.; Napoli, C.; Rutigliano, S.; Lopuzzo, M.; Lovero, G.; Montagna, M.T. Aflatoxin contamination in nuts marketed in Italy: Preliminary results. Ann. Ig. 2018, 30, 401-409. [CrossRef]

34. International Agency for Research on Cancer (IARC). Some Naturally Occurring Substances: Food Items and Constituents, Heterocyclic Aromatic Amines and Mycotoxins. IARC Monographs on the Evaluation of Carcinogenic Risks to Humans; International Agency for Research on Cancer (IARC): Lyon, France, 1993; Volume 56, pp. 1-609.

35. Rajkowska, K.; Kunicka-Styczyńska, A. Typing and virulence factors of food-borne Candida spp. isolates. Int. J. Food Microbiol. 2018, 279, 57-63. [CrossRef]

36. Deng, Y.; Liu, Y.; Jiang, Z.; Wang, J.; Zhang, Q.; Qian, Y.; Yuan, Y.; Zhou, X.; Fan, G.; Li, Y. A multiplex loop-mediated isothermal amplification assay for rapid detection of Bacillus cereus and Staphylococcus aureus. Biosci. Trends 2019, 13, 510-515. [CrossRef]

37. Dewey-Mattia, D.; Manikonda, K.; Hall, A.J.; Wise, M.E.; Crowe, S.J. Surveillance for Foodborne Disease Outbreaks-United States, 2009-2015. MMWR Surveill. Summ. 2018, 67, 1-11. [CrossRef]

38. Webb, M.D.; Barker, G.C.; Goodburn, K.E.; Peck, M.W. Risk presented to minimally processed chilled foods by psychrotrophic Bacillus cereus. Trends Food Sci. Technol. 2019, 93, 94-105. [CrossRef] [PubMed]

39. EFSA Panel on Biological Hazards (BIOHAZ). Risks for public health related to the presence of Bacillus cereus and other Bacillus spp. including Bacillus thuringiensis in foodstuffs. EFSA J. 2016, 14, 93. 
40. Caggiano, G.; Dambrosio, A.; Ioanna, F.; Balbino, S.; Barbuti, G.; De Giglio, O.; Diella, G.; Lovero, G.; Rutigliano, S.; Scarafile, G.; et al. Prevalence and Characterization of Methicillin-Resistant Staphylococcus aureus Isolates in Food Industry Workers. Ann. Ig. 2016, 28, 8-14. [CrossRef] [PubMed]

41. Orsi, R.H.; Wiedmann, M. Characteristics and distribution of Listeria spp., including Listeria species newly described since 2009. Appl. Microbiol. Biotechnol. 2016, 100, 5273-5287. [CrossRef]

42. den Bakker, H.C.; Cummings, C.A.; Ferreira, V.; Vatta, P.; Orsi, R.H.; Degoricija, L.; Barker, M.; Petrauskene, O.; Furtado, M.R.; Wiedmann, M. Comparative genomics of the bacterial genus Listeria: Genome evolution is characterized by limited gene acquisition and limited gene loss. BMC Genom. 2010, 11, 688. [CrossRef]

43. Johnson, J.; Jinneman, K.; Stelma, G.; Smith, B.G.; Lye, D.; Messer, J.; Ulaszek, J.; Evsen, L.; Gendel, S.; Bennett, R.W.; et al. Natural atypical Listeria innocua strains with Listeria monocytogenes pathogenicity island 1 genes. Appl. Environ. Microbiol. 2004, 70, 4256-4266. [CrossRef]

44. Perrin, M.; Bemer, M.; Delamare, C. Fatal case of Listeria innocua bacteremia. J. Clin. Microbiol. 2003, 41, 5308-5309. [CrossRef]

45. Caggiano, G.; De Giglio, O.; Lovero, G.; Rutigliano, S.; Diella, G.; Balbino, S.; Napoli, C.; Montagna, M.T. Detection of Listeria monocytogenes in ready-to-eat foods sampled from a catering service in Apulia, Italy. Ann. Ig. 2015, 27, 590-594. [CrossRef]

46. Keys, A.L.; Dailey, R.C.; Hitchins, A.D.; Smiley, R.D. Postenrichment population differentials using buffered Listeria enrichment broth: Implications of the presence of Listeria innocua on Listeria monocytogenes in food test samples. J. Food Prot. 2013, 76, 1854-1862. [CrossRef]

47. Dailey, R.C.; Welch, L.J.; Hitchins, A.D.; Derike Smiley, R. Effect of Listeria seeligeri or Listeria welshimeri on Listeria monocytogenes detection in and recovery from buffered Listeria enrichment broth. Food Microbiol. 2015, 46, 528-534. [CrossRef]

48. Maggio, A.; Roscigno, G.; Bruno, M.; De Falco, E.; Senatore, F. Essential-Oil Variability in a Collection of Ocimum basilicum L. (Basil) Cultivars. Chem. Biodivers. 2016, 13, 1357-1368. [CrossRef] [PubMed]

49. Sakkas, H.; Papadopoulou, C. Antimicrobial Activity of Basil, Oregano, and Thyme Essential Oils. J. Microbiol. Biotechnol. 2017, 27, 429-438. [CrossRef] [PubMed]

50. Zulfqar, F.; Akhtar, M.F.; Saleem, A.; Akhtar, B.; Sharif, A.; Saleem, U. Chemical Characterization, Antioxidant Evaluation, and Antidiabetic Potential of Pinus Gerardiana (Pine Nuts) Extracts. J. Food Biochem. 2020, 44, e13199. [CrossRef] [PubMed]

51. Amin, F.; Masoodi, F.A.; Baba, W.N.; Khan, A.A.; Ganie, B.A. Effect of different ripening stages on walnut kernel quality: Antioxidant activities, lipid characterization and antibacterial properties. J. Food Sci. Technol. 2017, 54, 3791-3801. [CrossRef]

52. Aung-aud-chariya, A.; Bangrak, P.; Lumyong, S.; Phupong, W.; Aggangan, N.S.; Kamlangdee, N. RNA Polymerase II Second Largest Subunit Molecular Identification of Boletus Griseipurpureus Corner from Thailand and Antibacterial Activity of Basidiocarp Extracts. Jundishapur J. Microbiol. 2015, 8, e15552. [CrossRef]

(C) 2020 by the authors. Licensee MDPI, Basel, Switzerland. This article is an open access article distributed under the terms and conditions of the Creative Commons Attribution (CC BY) license (http://creativecommons.org/licenses/by/4.0/). 